\title{
Modelling the employed in the Russian economy given the impact of pension reform and the coronavirus pandemic
}

\author{
Eugene Pitukhin ${ }^{1, *}$, Marina Astafyeva ${ }^{2}$, and Maxim Kukolev ${ }^{3}$ \\ ${ }^{1}$ Petrozavodsk State University, Petrozavodsk, Russia \\ ${ }^{2}$ Dubna State University, Protvino, Russia \\ ${ }^{3}$ Peter the Great St. Petersburg Polytechnic University, St. Petersburg, Russia
}

\begin{abstract}
The article is devoted to forecasting changes in the number of people employed in the economy of the Russian Federation, which should occur as a result of the effects of the pension reform in 2018 and also the coronavirus pandemic in 2020. The demographic forecast of the population of the Russian Federation until 2030 is used as the dominant forecasting factor. The influencing factors on the process dynamics are the employment levels. The forecast of employment levels is based on the factors of the pension reform in 2018 and the coronavirus pandemic in 2020. The following trends are also being demonstrated: an increase in employment due to "former" pensioners remaining in work, and a decline in employment due to an increase in the number of unemployed because of coronavirus pandemic. For the duration of the pension reform, the economy's annual need for human resources will decrease. This will cause difficulties in finding a job for the majority of applicants - graduates of the vocational education system. The situation will be further aggravated by rising unemployment due to the reduction of jobs in the economy caused by the coronavirus pandemic.
\end{abstract}

\section{Introduction}

The main works of domestic scientists in the field of forecasting the aggregate and current demand for personnel, studying the labor market and modeling the dynamics of employment include A.G. Korovkin [1-2]. Modeling of employment levels and economic activity of the population using econometric dependencies on income and wage factors was carried out in the works of S.G. Kuznetsov et al. [3-4]. In the article [5] A.V. Kashepov provides a predictive assessment of the prospective labor demand of the Russian economy, and in [6], based on an analysis of employment, forecasts are made of the number of young people and students, educators for the period up to 2030. The need for prediction of employees to increase the effectiveness of using the potential of the regional economyindicates S.N. Sakhnov in [7]. In the work of N.V. Popova [8] employment levels are noted as one of the factors in the regulation of social and labor relations in society.

\footnotetext{
*Corresponding author: eugene@petrsu.ru
} 
In studies of demographers [9], it is shown that a decrease in the birth rate and an increase in life expectancy lead to an increase in the share of elderly and old people in the population. Obviously, the aging process also affects both the economically active and the occupied population of Russia. So, in the work of I.A. Elshina [10] considers the problem of increasing the employment of persons of retirement and pre-retirement age in the context of demographic aging of the population and a shortage of labor resources. Research Yu.V. Sonina [11] testifies to the aging of the workforce in Russia as a result of both the general aging of the population and an increase in the level of economic activity of older people.

The problem of aging of the employed population is also present in foreign countries. In [12], it is noted that according to OECD data, over the past 10-15 years, the economic activity of older people has increased in many developed countries, which led to the Ushaped dynamics of the economic activity of the elderly [13].

In a previous study [14], the author of this article with colleagues presented a methodology for predicting changes in the number of people employed in the economy based on extrapolation of employment levels of permanent residents aged 15 to 72 years in the context of five-year-old age and gender groups. Since, according to the current program [15], the retirement age in the transitional period until 2028 will increase every two years, modeling of the annual change in the number of employees must be carried out according to one-year, and not five-year, age categories.

These circumstances led to the need to calculate the forecast number of employees taking into account the new conditions, as well as to determine the coefficients of the annual inflow and outflow of the number of employees and the associated indicator of the annual additional demand of the economy for personnel [16].

\section{Materials and Methods}

As an information base of the study, open data from the federal state statistics service were used $[17,18]$.

The basis for modeling is the demographic forecast of the Russian population until 2035 [17] for both genders in the context of annual age categories from 0 to 100 years. Based on data on the structure of employed by age groups and the total number of employed [18], the number of employed by age groups for 2014-2016 is determined separately for men and women.

Further, for the corresponding age groups, employment levels for both genders are calculated. Due of the stabilization and decline in employment levels during the crisis of 2008-2010, we can assume that the further growth of employment also will be stabilize even in the current crisis. Based on this, an assumption is made on stabilization of the employment forecast at the level of 2015-2019. Thus, the forecast employment levels for all age categories are set constant throughout the forecasting period until 2030.

The next assumption of the model is the interpolation of the values of employment levels of five-year-old age and gender categories by the values of one-year levels. If the factors of the impact of the pension reform 2018 (PR) and the pandemic of coronavirus 2020 are not taken into account, then the values of the employment levels would be extrapolated as constants until 2030. Thus, the projected number of employees would be calculated by multiplying the projected population in one-year age and gender categories by the corresponding projected employment levels in these age and gender categories.

The demographic forecast is compiled by the federal state statistics service using the well-known method of moving ages and the Leslie model. We will forecast employment levels by extrapolation methods, based on published official information on the annual impact of pension reform, as well as forecasts by experts from the Ministry of Labor on the expected level of registered unemployment by the end of $2020[19,20]$ and the minimum 
period for the Russian economy to recover from recession [21]. In the study of the stochastic version of the model using simulation methods, the values of employment levels were taken as random variables with the distribution law determined on ten-year retrospective data.

\subsection{Forecasting model of the projected number of people employed in the economy}

Denote the variables: $p_{m, a, t}-$ number of men of age $a$ at $t$ th year; $p_{f, a, t}-$ number of women of age $a$ at $t$ th year; $c_{m, a, t}^{*}, c_{m, a, t}$ - employment rate for men of age $a$ at $t$ th year before and after the pension reform, respectively; $c_{f, a, t}^{*}, c_{f, a, t}-$ employment rate of women of age $a$ at $t$ th year before and after the pension reform, respectively.

The forecast period is set by the interval $t \in\left[t_{0}, t_{f}\right]$ where $t_{0}=2018, t_{f}=2030$. The range of changes in the age of employees is limited to the working-age population: $a \in\left[a_{b}, a_{e}\right]$ where $a_{b}=15$ years, $a_{e}=72$ years. Index $g \in\{m, f\}$ sets the gender sign: $m-$ male, $f$-female. The asterisk * indicates the value of the coefficient before the start of the pension reform.

When analyzing the employment of persons of retirement age, it should be noted that when retiring before the start of the pension reform, the employment levels for men and women change differently. The main retirement age for men in Russia was 60 years old, and the transition from the "55-59" category to the "60-64" category corresponded to a decrease in the employment rate from $c_{m, 59, t}^{*}=75.2 \%$ to $c_{m, 60, t}^{*}=27.2 \%$, i.e. almost 3 times. For women, upon retirement, when moving from the "50-54" category to "55-59", the level of employment decreased from $c_{f, 54, t}^{*}=85.5 \%$ to $c_{f, 55, t}^{*}=52.4 \%$, which amounted to only about $40 \%$. Starting the pension reform will change the level of employment of retirement age categories in past. We assume that it will increase to the level of previous age categories. That is, the new employment rate for men in the category "60-64" $c_{m, 60-64, t}$ will stay at the level $c_{m, 59, t}^{*}$ in the category "55-59", while for women in the category "55-59" the new employment rate $c_{f, 55-59, t}$ will stay at the level $c_{f, 54, t}^{*}$ in the category "50-54". According to the table for raising the retirement age [15] and the assumption made, we will make changes to previously constant forecast employment levels for the respective ages:

$$
c_{g, s, t}=\left\{\begin{array}{ll}
c_{g, s, t}^{*} & \mid t \in\left[t_{0}, t_{0}+2 n-1\right] \\
c_{g, s-n, 2020}^{*} & \mid t \in\left[t_{0}+2 n, t_{f}\right]
\end{array}, s=\left\{\begin{array}{ll}
59+n & \mid g=m \\
54+n & \mid g=f
\end{array}, n \in[1,5] .\right.\right.
$$

One of the first attempts to forecast the impact of the coronavirus pandemic on the Russian economy and labor market was made by the Minister of Labor and Social Protection A. Kotyakov. According to him, at the end of April - beginning of May 2020, the number of unemployed amounted to 3.7 million people, and by the end of 2020 - the beginning of 2021 the number of unemployed will increase to 5-6 million people [19].

Based on this statement, it is possible to estimate the value of the additional influx of unemployed in 2020 in the amount of 2 million people. Then it is logical to assume that for the same 2 million people the number of people employed in the Russian economy will fall. 
According to the Government of the Russian Federation, in a positive scenario (one wave of coronavirus), the exit from the recession will last for two years. If the second wave comes, then according to independent experts, the way out of the recession may last up to seven years [21]. By averaging the scenarios, we assume that the exit from the recession may last 4 years. In this case, in 4 years 2 million people should return to the economy. Under the assumption of a uniform distribution, each year from 2021 to 2024 the number of people employed in the economy will grow by 500 thousand people and by 2025 will go back to the highway.

Thus, the schedule of $\Delta L c v d_{t}$ growth factor in the number of people employed in the Russian economy from 2020 to 2030 due to the impact of the coronavirus pandemic will look like this (Fig. 1).

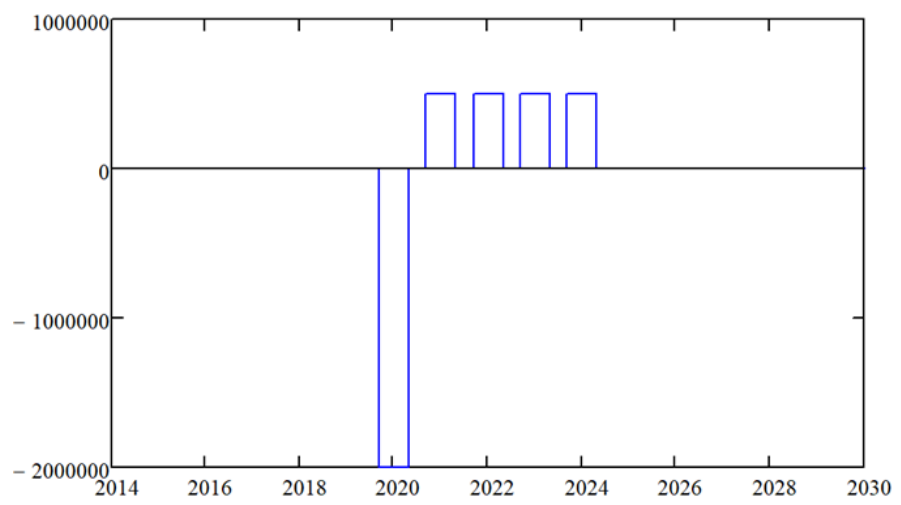

Fig. 1. Factor $\Delta L c v d_{t}$ in employment growth due to the 2020 coronavirus pandemic.

Based on this scenario, to account for the coronavirus 2020 pandemic, correction coefficients $c v d_{t}$ are calculated that correct the forecast number of employed models after working out the coronavirus scenario:

$$
c v d_{t}=1+\sum_{k=t_{0}}^{t} \Delta L c v d_{t} / \sum_{g} \sum_{a} L_{g, a, t}, g \in\{m, f\}, a \in\left[a_{b}, a_{e}\right], t \in\left[t_{0}, t_{f}\right] .
$$

So, as a result of multiplying the annual forecast employment levels (1) by the forecast values of the population of the corresponding age and gender, a population employment forecast is formed for the annual gender and age categories with correction for the impact of coronavirus (2):

$$
L_{g, a, t}=c v d_{t} \cdot c_{g, a, t} \cdot p_{g, a, t}, g \in\{m, f\}, a \in\left[a_{b}, a_{e}\right], t \in\left[t_{0}, t_{f}\right],
$$

Final forecasts of the employed population of Russia for both genders were obtained by summarizing forecasts for individual ages (3)

$$
L_{g, t}=\sum_{a} L_{g, a, t}, g \in\{m, f\}, a \in\left[a_{b}, a_{e}\right], t \in\left[t_{0}, t_{f}\right] .
$$




\subsection{Forecasting model of the inflow and outflow intensities of employed people to the labor market}

The study of the inflow and outflow coefficients of employed people provides an understanding of the formation processes of the total number of employed in the labor market of the Russian Federation.

To determine these coefficients, it is necessary to establish the volumes of inflow and outflow of people employed in the economy from the corresponding age-old equations of the balance of labor resources

$$
\begin{gathered}
L_{g, a+1, t+1}=L_{g, a, t}+\Delta L_{g, a, t}, g \in\{m, f\}, a \in\left[a_{b}, a_{e}-1\right], t \in\left[t_{0}, t_{f}-1\right], \\
\Delta L_{g, a, t}=L_{g, a, t}^{\text {in }}-L_{g, a, t}^{\text {out }}, g \in\{m, f\}, a \in\left[a_{b}, a_{e}\right], t \in\left[t_{0}, t_{f}\right],
\end{gathered}
$$

where from (5) and (6) are the annual gains or differences expressed:

$$
\Delta L_{g, a, t}=L_{g, a+1, t+1}-L_{g, a, t}, g \in\{m, f\}, a \in\left[a_{b}, a_{e}-1\right], t \in\left[t_{0}, t_{f}-1\right] .
$$

To determine the volume of inflow of the entire employed population, it is proposed to summarize all positive differences from (7), and for the volume of outflow, all negative ones:

$$
\begin{aligned}
L_{t}^{i n} & =\sum_{g} \sum_{a} \Delta L_{g, a, t} \mid \Delta L_{g, a, t}>0, g \in\{m, f\}, a \in\left[a_{b}, a_{e}-1\right], t \in\left[t_{0}, t_{f}-1\right], \\
L_{t}^{o u t} & =\sum_{g} \sum_{a} \Delta L_{g, a, t} \mid \Delta L_{g, a, t}<0, g \in\{m, f\}, a \in\left[a_{b}, a_{e}-1\right], t \in\left[t_{0}, t_{f}-1\right],
\end{aligned}
$$

where from (8) and (9) are the inflow coefficients $k_{L}^{\text {in }}$ and outflow $k_{L}^{\text {out }}$ employed are determined taking into account (4) in the form of relations (4)

$$
k_{L}^{\text {in }}=\frac{L_{t}^{\text {in }}}{\sum_{g} L_{g, t}}, k_{L}^{\text {out }}=\frac{L_{t}^{\text {out }}}{\sum_{g} L_{g, t}}, t \in\left[t_{0}, t_{f}-1\right] .
$$

\section{Results and Discussions}

Based on the obtained models (1)-(4), two variants of the forecast of changes in the number of employees are constructed: taking into account the 2018 pension reform and without it. Without taking into account the pension reform, the total number of employed men and women, starting in 2019, would fall at the same pace at a speed of about 440 thousand people a year, and by 2030 it would decrease by 4.8 million people. After the adoption of the pension reform, the average rate of decrease in the number of employees will drop significantly and will reach about 150 thousand people per year. With this scenario, the number of employees by 2030 , compared with 2019 , will be reduced by only 1.6 million people. Thus, thanks to the pension reform, the country's economy will receive a bonus in the form of "additional" 3.2 million workers by 2030, which can be described as a strengthening of the country's extensive development strategy. 
The "sawtoothness" of the predicted dynamics of the number of employees taking into account PR is well explained by analyzing the coefficients of inflow and outflow of employees (10) (Fig. 2).

The predicted behavior of the coefficient of outflow of the number of employed in Russia according to the scenario without PR varies insignificantly and fluctuates around 3\% of the total employed population. The inflow rate in this scenario grows from $2.1 \%$ to $2.6 \%$, but still does not reach the level of 3\%. In the case of the implementation of the PR scenario, the inflow coefficient behaves in the same way as without the PR. Of particular interest is the behavior of the coefficient of outflow of employed population in the case of PR. It behaves "sawtooth", changing its value from 3\% in even years of the transition period to $2 \%$ in odd years, when it takes a value less than the influx coefficient. Thus, a "sawtooth" behavior of the number of people employed in Russia is formed, taking into account the effects of PR.

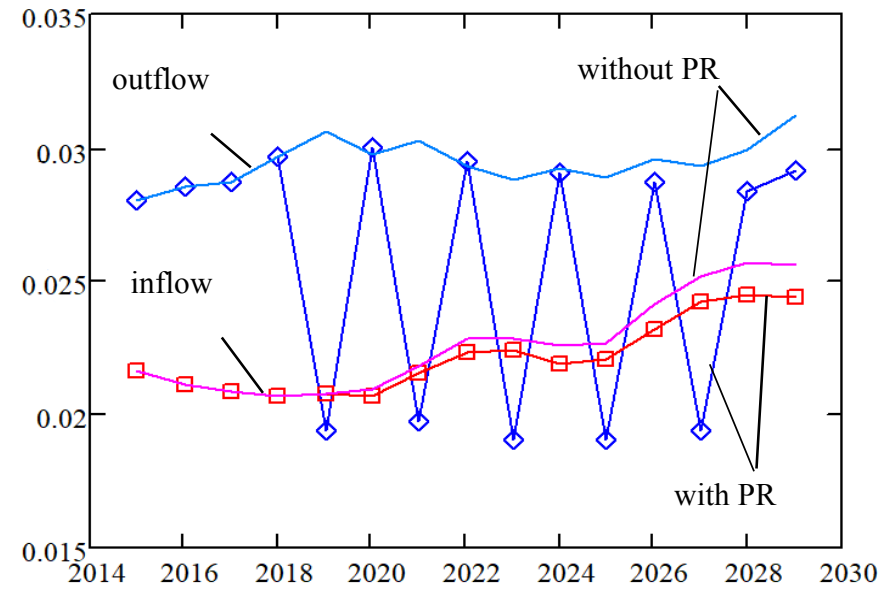

Fig. 2. Forecast of the coefficients of inflow and outflow employed population of Russia.

Taking into account the impact of the coronavirus pandemic on the economy and the labor market is shown in the following graph (Fig. 3), illustrating the change in the forecast number of people employed in the Russian economy due to various factors.

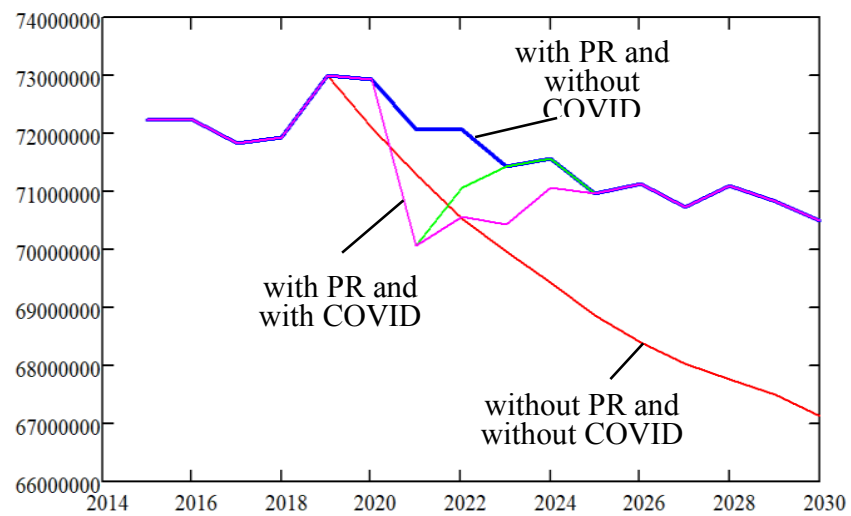

Fig. 3. Scenarios of changes in the forecasted number of employed in the Russian economy.

The red curve indicates a decline in the number of people employed in the Russian economy if PR 2018 had not been adopted. The pension reform in 2018 can compensate for 
the decline in the number of employees by adding about 3 million people by 2030. (blue curve). According to the Federal Statistics Service, by the beginning of 2020 the number of employees should be 72.7 million people, according to our model, the number of employees was 72.9 million people.

The intervention of the COVID-19 pandemic in the Russian economy will not allow keeping the number of employed at the level of 72 million people. An increase in unemployment will entail a decrease in the number of people employed in the labor market to about 70 million people by the beginning of 2021 (magenta curve). This trend plans to exit the recession in four years and exit to the highway by 2025 . The green curve shows the way out of the recession in just 2 years and the exit to the highway by 2023 .

\section{Conclusion}

In the case of the implementation of the Russian pension reform in 2018, the additional staffing requirement will have an oscillatory "sawtooth" character. In even years (2020, $2022,2024,2026,2028$ ) of the reform period, the annual need will be at the level of 2 million people, which corresponds to the pre-reform level. But in odd years $(2019,2021$, $2023,2025,2027)$ the annual additional need for the Russian economy in personnel will be reduced by as much as $30 \%$, that is, by almost 700 thousand people, and will amount to about 1.3 million people. Such a decrease in the need for personnel will be an unpleasant surprise for young people - graduates of the vocational education system who are counting on vacant jobs due to retirement. Instability caused by supply and demand in the labor market, alternating over years, it will create difficulties for the employment of graduates of higher and secondary vocational education. This can lead to unpredictable consequences on the labor market, an increase in youth unemployment and an increase in social tension in society. The coronavirus pandemic will cause a temporary decline in the number of employees of about 2 million people, but this will be within the compensation for the increase in the number of employees due to the effects of pension reform.

\section{References}

1. A.G. Korovkin, Employment and labor market dynamics: macroeconomic analysis and forecasting, 320 (2001)

2. A.G. Korovkin, Studies on Russian Economic Development, 24(4), 353 (2013)

3. S.G. Kuznetsov, A.S. Semenov, Man and labor, 9, 35 (2001)

4. S.G. Kuznecov, Methodology of macroeconomic analysis and forecasting of labor demand and supply, 36 (2005)

5. A.V. Kashepov, Bulletin of the Russian New University, 2, 7 (2012)

6. A.V. Kashepov, Bulletin of the Russian New University, 4, 9 (2017)

7. S.N. Sakhnov, Don's Engineering Bulletin, 4 (2012), http://www.ivdon.ru/

8. N.V. Popova, Don's Engineering Bulletin, 4 (2012), http://www.ivdon.ru/

9. Demoscope Weekly, http://demoscope.ru/

10. I.A. Elshina, Strategy for sustainable development of Russian regions, 28, 124 (2015)

11. Yu.V. Sonina, Statistics issues, 5, 48 (2015)

12. OECD, http://www.oecd.org/

13. U. Hotopp, The Employment Rate of Older Workers. Labor Market Trends, 2, 73 (2005) 
14. D.M. Moroz, M.P. Astafieva, E.A. Pitukhin, Basic research, 12, 67 (2015)

15. Main RBC, URL: https://www.rbc.ru/

16. V.A. Gurtov, E.A. Pitukhin, L.M. Serova, Studies on Russian Economic Development, 18 (6), 622 (2007)

17. Demographic forecast until 2035. Federal state statistics service, http://www.gks.ru/

18. Federal state statistics service (2017), www.gks.ru/

19. In Russia, the number of unemployed reached 1.2 million people, https://p.dw.com/

20. Up-to-date information about the situation on the labor market of the Russian Federation, https://rosmintrud.ru/

21. The second wave of coronavirus will bring Russia a prolonged recession, http://www.ng.ru/ 